\title{
Videographic conceptual dynamic representation of bicuspid aortic valve anatomic configurations and structural inter-relationships
}

Y. Joseph Woo, MD, ${ }^{\mathrm{a}, \mathrm{b}}$ Michael J. Paulsen, MD, ${ }^{\mathrm{a}}$ Laurent de Kerchove, MD, PhD, ${ }^{\mathrm{c}}$ and Yuanjia Zhu, MD, ${ }^{\mathrm{a}, \mathrm{b}}$ Stanford, Calif, and Brussels, Belgium

From the Departments of ${ }^{\mathrm{a} C a r d i o t h o r a c i c ~ S u r g e r y ~ a n d ~}{ }^{\mathrm{b}}$ Bioengineering, Stanford University, Stanford, Calif; and ${ }^{c}$ Department of Cardiovascular and Thoracic Surgery, Cliniques Universitaires Saint-Luc, Université Catholique de Louvain, Brussels, Belgium.

Disclosures: The authors reported no conflicts of interest.

The Journal policy requires editors and reviewers to disclose conflicts of interest and to decline handling or reviewing manuscripts for which they may have a conflict of interest. The editors and reviewers of this article have no conflicts of interest.

Received for publication April 27, 2021; accepted for publication June 16, 2021; available ahead of print June 24, 2021.

Address for reprints: Y. Joseph Woo, MD, Department of Cardiothoracic Surgery, Falk Cardiovascular Research Center, Stanford University School of Medicine, 300 Pasteur Dr, Stanford, CA 94305 (E-mail: joswoo@ stanford.edu).

JTCVS Techniques 2021;9:44-5

2666-2507

Copyright $(2021$ The Author(s). Published by Elsevier Inc. on behalf of The American Association for Thoracic Surgery. This is an open access article under the CC BY-NC-ND license (http://creativecommons.org/licenses/bync-nd/4.0/).

https://doi.org/10.1016/j.xjtc.2021.06.019

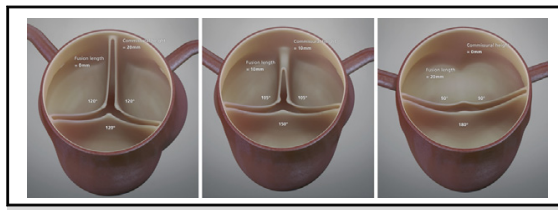

The transition of a normal aortic valve through type 1 into type o bicuspid aortic valve.

\section{CENTRAL MESSAGE}

We present a video that depicts the continuous spectrum of anatomic relationships in normal, type 1 , and type o bicuspid aortic valves.

See Commentaries on pages 46 and 48 .
Video clip is available online.

Bicuspid aortic valve (BAV) disease, classified by Sievers and Schmidtke, ${ }^{1}$ encompasses a wide span of abnormal anatomy with intermediary configurations including varying states of sclerosis and calcification. Recognition has evolved greatly that the scope of different configurations has significant clinical impact on therapeutic interventions, such as aortic valve repair and transcatheter aortic valve replacement. For example, the circumferential geometric reimplantation of a BAV into a graft during aortic valve repair and valve-sparing aortic root replacement ${ }^{2}$ has been guided in part by the anatomic configuration of the BAV. ${ }^{3}$

To advance the understanding of BAV configurations, we employed intraoperative measurements ${ }^{4}$ and synthesized a video that provides a conceptual dynamic representation of the structural inter-relationship of circumferential angles, cusp fusion length, and commissural fusion height in normal aortic valves, type 1 , and type 0 BAVs (Video 1). This video depicts a transition of normal tricuspid aortic

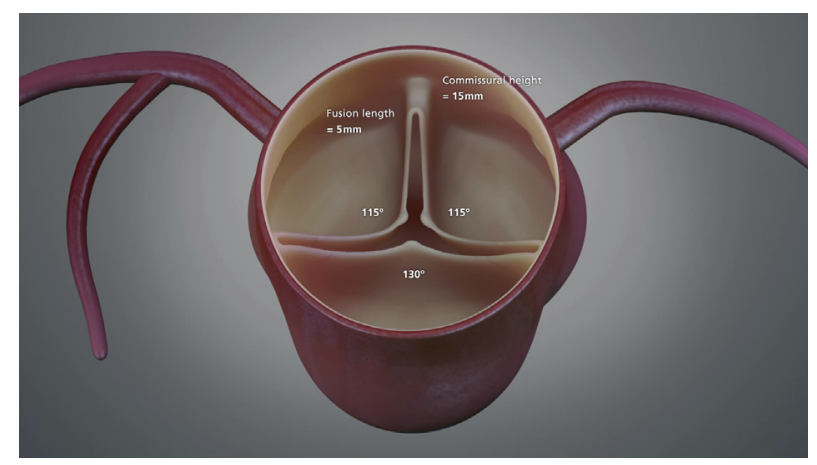

VIDEO 1. Animated video that provides a conceptual dynamic representation of the structural inter-relationship of circumferential angles, cusp fusion length, and commissural fusion height in normal aortic valves, type 1 , and type 0 bicuspid aortic valves. Video available at: https:// www.jtcvs.org/article/S2666-2507(21)00417-X/fulltext.

valve with a commissure angle of $120^{\circ}$ through type 1 with pauses at commissure angle $130^{\circ}, 150^{\circ}$, and $170^{\circ}$ to highlight very asymmetric, asymmetric, and symmetric type $1 \mathrm{BAVs}$, respectively, and finishes with a $180^{\circ}$ type 0 BAV. Note that the pauses in this video do not to convey an actual pathophysiologic event but to convey the presence of a continuous spectrum of anatomic relationships, reflecting the 3 new general BAV categories. ${ }^{3}$ 
One can envision how very asymmetric BAVs can be repaired toward a tricuspid configuration, and symmetric BAVs can be repaired toward a $180^{\circ} / 180^{\circ}$ configuration and other permutations such as bicuspidization of an unequal tricuspid valve. ${ }^{5}$ The type $1 \mathrm{BAV}$ configuration was modeled ex vivo and demonstrated clinically relevant aortic regurgitation from fused cusp prolapse, which was successfully repaired. ${ }^{6}$ This video represents a visual tool that can provide important conceptual understanding of the continuous spectrum of BAV and can aid in the surgical care of this complex patient population.

\section{References}

1. Sievers HH, Schmidtke C. A classification system for the bicuspid aortic valve from 304 surgical specimens. J Thorac Cardiovasc Surg. 2007;133:1226-33.
2. Paulsen MJ, Imbrie-Moore AM, Baiocchi M, Wang H, Hironaka CE, Lucian HJ, et al. Comprehensive ex vivo comparison of 5 clinically used conduit configurations for valve-sparing aortic root replacement using a 3-dimensional-printed heart simulator. Circulation. 2020;142:1361-73.

3. Jahanyar J, el Khoury G, de Kerchove L. Commissural geometry and cusp fusion insights to guide bicuspid aortic valve repair. J Thorac Cardiovasc Surg Tech. 2021;7:83-92.

4. de Kerchove L, Mastrobuoni S, Froede L, Tamer S, Boodhwani M, van Dyck M, et al. Variability of repairable bicuspid aortic valve phenotypes: towards an anatomical and repair-oriented classification. Eur J Cardiothorac Surg. February 20, 2019; ezz033.

5. Woo YJ, Frederick JR. Valve-sparing aortic root replacement and neochordal repair of complex aortic leaflet pathology for ruptured sinus of Valsalva aneurysm fistulizing to the right ventricle. Ann Thorac Surg. 2013;96:1891-3

6. Zhu Y, Imbrie-Moore AM, Paulsen MJ, Priromprintr B, Wang H, Lucian HJ, et al. Novel bicuspid aortic valve model with aortic regurgitation for hemodynamic status analysis using an ex vivo simulator. J Thorac Cardiovasc Surg. June 29, 2020 [Epub ahead of print]. 